\title{
Bus accessibility planning in Iran: the case of Mashhad
}

\author{
M. R. Rahnamma \\ Department of Urban Geography, Ferdowsi University of Mashhad, Iran
}

\begin{abstract}
The planning of bus accessibility, due to the observing of social and economical matters and joining of urban land use and the transport system, has an essential position in the planning and designing process of the city. The importance of this matter has been highly recognized since the 1950 's, especially after the criticism of the city designing model based on the Auto City, because it caused the horizontal expansion of the cities (sprawl), environmental pollution, separation of the work place and houses and increasing transport costs. The purpose of this research is to evaluate accessibility based on the bus system in the City of Mashhad, to determine the direct inaccessible regions for citizens to the bus system and also to determine the ideal radius accessibility and to design the best route for buses. To achieve this purpose the reformed Hansen and Pooler model was used (Hansen 1959 and Pooler 1995), which was based on population variables, occupation and by calculating the potential attraction and the distance between different municipal regions in Mashhad (12 regions) which was completed with the help of a Geographical Information System (GIS). The results of the usage of this model in Mashhad indicate that after personal transportation (27\% of all trips), buses are the main use for public transportation with which $24 \%$ of all daily trips are made, $88 \%$ of the expansion and $86 \%$ of the citizens have direct accessibility to buses, meaning that 25,49 square kilometers and 342987 of citizens do not have direct accessibility to the bus system. Also the accessibility coefficient shows differences in different regions of the city. It shows an increase from the populated, low-income regions in the north-east towards the developing regions in the south-west and west of the city. Finally, creating new bus lines and changing the current ones, to cover the regions without direct accessibility to buses, is an effective step towards creating the sustainable development of the city.
\end{abstract}

Keywords: planning, accessibility, bus, City of Mashhad. 


\section{Introduction}

Today, buses are one of the most important means of public transportation in most cities. Certain factors have caused citizens to have more accessibility to these transportations because of technological and infrastructural changes. 1- Buses with low floors, 2- Completely accessible bus stops (Salvo and Sabitini [1]). About bus accessibility, not only are topics like equality in bus accessibility for various classes of society and stopping time put forward but also topics like bus system covered city space and the relation between bus stops and populated centers and occupation.

A brief evaluation of the share of public transportation in the cities of developed countries indicates that in cities like Rome, they take up only $40 \%$ of all trips; meanwhile $60 \%$ of all trips are taken by private cars. Or in Sydney, Australia approximately $70 \%$ of business trips are by car, $15 \%$ by train, $6 \%$ by bus and $9 \%$ by other means of transportation (A New South Wales Government Initiative [2]).

In Tehran $20 \%$ of all passenger transportation is by public transport (Tehran Bus Organization [3]).

In developed countries not only are the quantitative matters related to the public transport system (buses) like designing direct accessible routes to bus lines (passing of bus lines with a 300 to 400 meter radius from each other and or building stops with a $300 \mathrm{~m}$. or 5 minute walk to bus stops) and inaccessible boundaries in the public transportation taken into account, but qualitative matters like reducing delays, increasing the safety of bus stops and bus technology (buses with low floors for disabled groups) are important for the encouragement of the usage of buses in the city's transportation (Bus Stop Accessibility [4]).

In developing countries like Iran, not only are quantitative topics like recognizing inaccessible boundaries for bus routes, but also determining standards like building stops and passing of bus lines with a 300 to $400 \mathrm{~m}$. radius, going through their initial stages. In Tehran, the country's capital, even with the entry of buses to the city transport system from 1911, at present the Tehran bus company has approximately 17,000 personnel and 6500 buses and more than 300 lines and $2400 \mathrm{~km}$ of routes and is transporting 3 million people each day. Tehran needs an average of $330 \mathrm{~km}$ of special bus lines. The history of bus usage in the city of Mashhad goes back to 1939, with the usage of the first two buses. After that, the bus driving company was established in 1965 and in 1974 was changed to the bus driving organization, at present $24 \%$ of passengers are transported by bus by the Mashhad Bus Company [5]. The important point about the situation of the accessibility plan especially in Iran, is the small amount of scientific subject related to accessibility in the scientific literature of Iran, and what has been known as accessibility up to now, is more about the structural definitions related to passage accessibility and categorizing them in related topics to city designing; like the book: Principals and Methods of Accessibility Designing and Residential Space in Iran, which is related to this topic (Tavasoli [6]). In this research, by using the reformed Hansen and Pooler model, Ko-Wan 
Tsou et al [7], the accessibility to the bus driving system and the coefficient assessment based on occupation, has been evaluated.

\section{Research purpose}

1- Creating an intelligent and dynamic public transportation system map (bus routes)

2- Determining covered boundaries of routes and bus stops and estimating the area and city population of people who have no direct access to public transportation systems (buses).

3- Evaluating the accessibility coefficient by the Hansen and Pooler model and GIS and its changes from 1996 to 2005 in Mashhad based on population indices, employment and the distance between city regions (12 regions).

\section{The meaning and method of accessibility evaluation and its changes based on the bus driving system in Mashhad}

Accessibility has the meaning of "reaching easily to the destination", or "reducing costs in the destination" (Levine and Garb [8]). In another explanation accessibility means the freedom or capability of the people in assessing the main needs as long as they stabilize the quality of their life (Lau and Ciu [9]). Also, accessibility can be defined as proportional nearness or proximity of one location to another (place) [7]. The general meaning of accessibility is: easy access to different activities (Bordde Makri [10]). The general accessibility index equation is as follows:

$$
A_{I J}=\sum_{J} f\left(w_{j}, S_{i j}\right)
$$

$\mathcal{W}_{j}=$ the attraction index and $\boldsymbol{S}_{i j}=$ the spatial separating standard, for example it is the distance or time of the trip from $\mathrm{i}$ to $\mathrm{j}$.

$$
A_{I}=\sum_{J=1} F\left(S_{I J}\right)^{\text {в }}
$$

The place where the accessibility of $A$ in the $i$ situation is changed directly with $\boldsymbol{S}_{i j}$.

The B coefficient is equal to 2 [7].

In regard to the project's focus, the previous equation might have various applications, therefore different amounts of $\mathrm{Wj}$ and $\mathrm{Sij}$ will be obtained.

The planning of accessibility is related to the method where people with low incomes can receive goods like food and services, like medical care, or accommodations and essential services like places of occupation or institutes. The purpose of accessibility planning is to achieve sustainable city development by passing from "movement" or "speed increase" to "accessibility" or "reducing the distance between workplaces and residential areas" and consequently reducing fuel consumption and environmental pollution. Therefore this accessibility planning is a means of achieving sustainable city development. 
Reviewing accessibility literature, about meaning and usages is categorized into three groups:

1- Topics related to infrastructures (route system);

2- Topics related to activities like work and life, work, recreation and shopping;

3- Linking standards like distances between regions or industrial regions and bus stops or connections to highways are of this type (Ber van Wee et al [11]).

In this research standards related to infrastructures (population and employment) and linking standards (distance between offices and residential areas) are used.

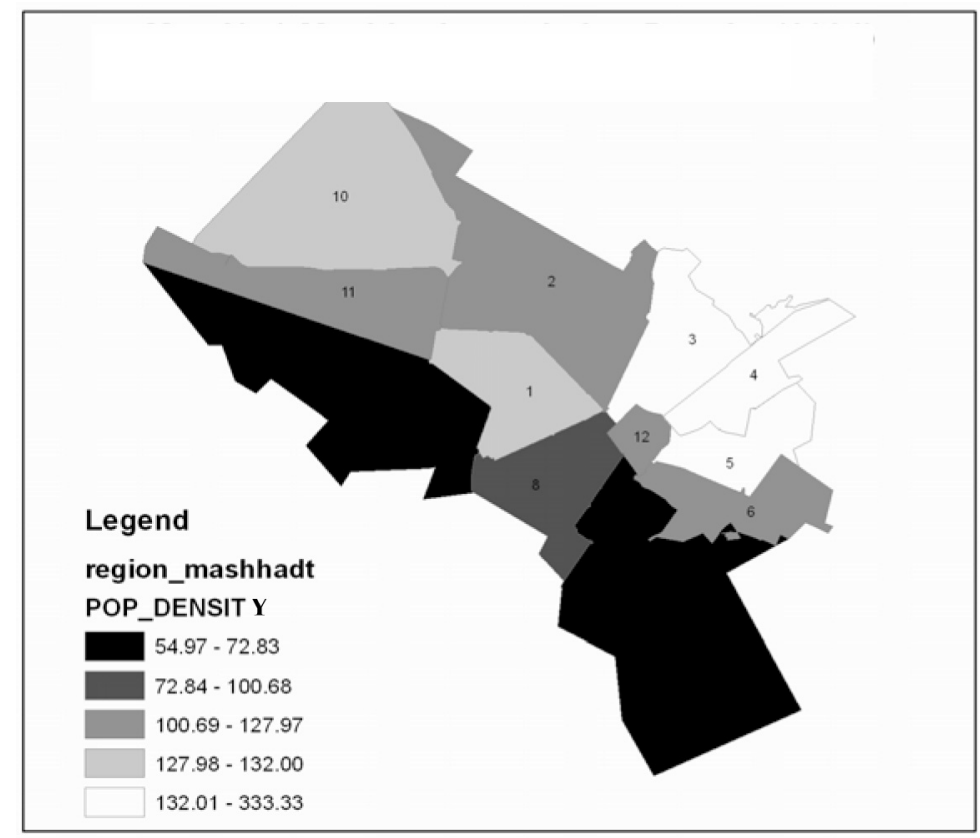

Figure 1: $\quad$ Mashhad population density (2005).

\section{A brief look at the City of Mashhad}

Mashhad is the second largest city in Iran and the biggest religious city in the country, because of the presence of the Holy Shrine of the Eighth Shiite Imam, with a 1200 year background (Imam [12]). This city has an area of 270 square $\mathrm{km}$ and its population was 1866300 in 1996, which was increased to 2395503 in 2005 (Transportation and Traffic Organization of the Mashhad Municipality Office [13]). This city, besides its permanent residents has approximately 13 million pilgrims and tourists because of the Holy Shrine. The distribution of the population and employments in Mashhad shows spatial irregularities, the northeastern regions are populated and dense, but the north-western and south-eastern regions are not populated. This condition can be seen in figure 1 . The regional distribution of the city's income shows a certain lack of coordinations, comparing 
the population density and per capita income indicates that dense over populated regions have a low income and less populated regions have a higher income.

In regard to the transportation system, Mashhad has no rail system (even though the preparations for establishing $18 \mathrm{~km}$ of city rails were being prepared, but are still not being operated). The most essential city transportation system is private cars with $27.8 \%$ of all trips being taken by them, which has increased by $7.8 \%$ from 1996-2005. Meanwhile, the use of the bus system has decreased by $1.8 \%$ with a $26 \%$ to $24,2 \%$ reduction [13].

Mashhad has 95 bus lines in the city and 32 lines in the suburbs, with 1200 buses in the city and 50 in the suburbs now being used, and the average speed for buses being $17.1 \mathrm{~km}$ per hour. The bus per capita is 3051 ; the average lifespan of a bus is 6.7 years. All the personnel in the bus system amount to 2971 people; the per capita bus passenger transport is 1150 per day. Also, the average number of trips in recent years has changed from 1.41 trips per person to 1.61 trips per person, an increase of $14 \%$.

\section{Calculating interaction between city regions (12 regions)}

The accessibility coefficient was evaluated between the minimum distances and city regions (12 regions) after creating 95 maps of bus routes, figure 2, and determining their centers from Centriods of the GIS and Arc view and joining city region centers to the bus system by creating $12 * 12$ matrices.

By the Distance Matrix the table of the shortest possible route was made. The preparations for determining the interaction between city regions were made based on the attraction model.

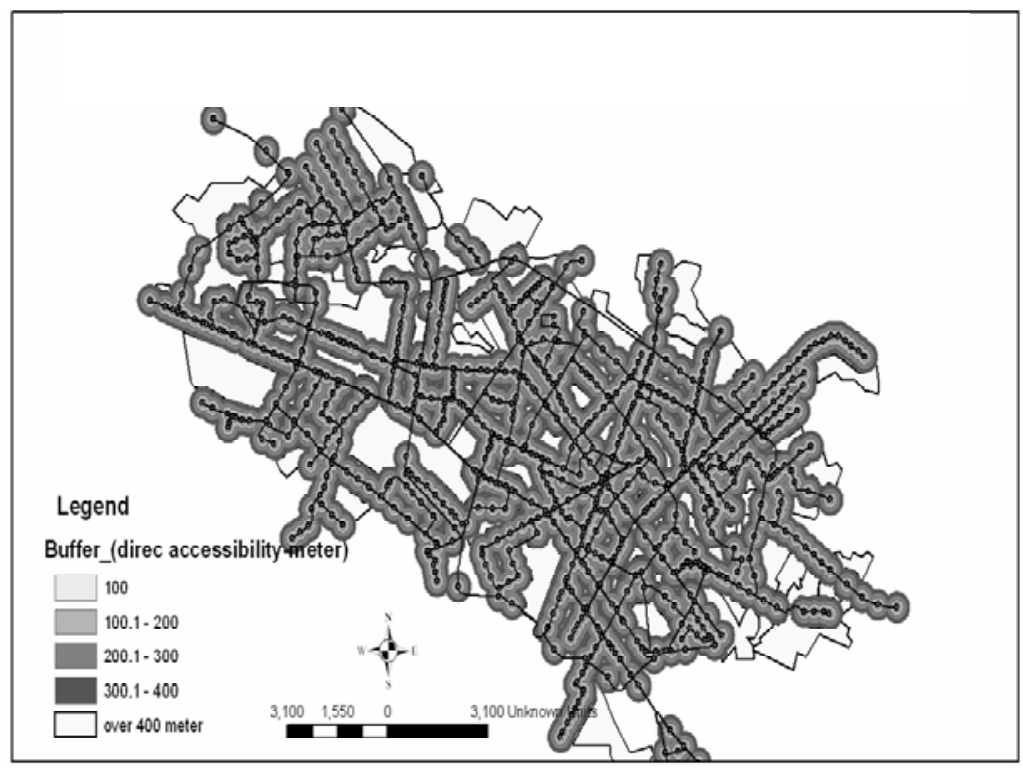

Figure 2: $\quad$ Mashhad bus direct accessibility (2005). 


\section{Calculating the direct accessibility to buses in Mashhad}

To calculate the direct accessibility, the scales were proposed by specialists, for example boundaries with a $300 \mathrm{~m}$ radius from the bus system axis routes or 5 minute walking distance from the bus stops were considered as standards for the direct accessibility of people [1]. In figure 2, the direct accessibility to routes and bus stops in 100, 200, 300 and 400 meter radii are shown individually. As we can tell by the map, 25.4 square $\mathrm{km}$ of Mashhad and about 342978 people from the Mashhad population had no direct accessibility to buses, in other words about $12 \%$ of the area and $14 \%$ of the population of Mashhad have no direct accessibility. Therefore planning to increase the coverage of the people to direct bus accessibility is urgent.

\section{Evaluating accessibility and its changes in Mashhad}

\subsection{Evaluating accessibility index in $\mathbf{1 3 7 5}$}

The results of calculating the accessibility coefficient based on the population in 1996 is clearly states that the 12, 4 and 5 regions with higher population and low income have a high accessibility coefficient; except for region 12 which is considered a part of the city center, the other two regions are on the north-eastern outskirts of the city. The north-western and south-eastern suburban regions have a low accessibility coefficient because of the low population and large distance from the city center. In this year, the accessibility coefficient based on employment, follows the accessibility coefficient of the population.

\subsection{Evaluating accessibility index in $\mathbf{1 3 8 4}$}

The results of the accessibility index evaluation based on the population in 2005 clearly indicate a high accessibility coefficient in regions numbered 5 and 11 and a low coefficient in region 7 in Mashhad. Having a large area, small population and being on the city outskirts are the main reasons for the low accessibility coefficients in region 7 .

The results of the index accessibility evaluation based on employment in 2005 clearly states that the accessibility coefficient of occupation from the population situation is the main point for having a high accessibility coefficient of employment in the city center towards the north-west. The regions with a low accessibility coefficient of employees are the municipal regions of 7 and 10.

\section{Evaluating accessibility changes in Mashhad municipal regions from 1996 to 2005}

One of the purposes of the research, besides evaluating accessibility coefficients, is to evaluate its changes from 1996 to 2005 in municipal regions, which has been done by the following equation (Rahnamma and Lyth [14]): 


$$
R=\left(P_{1+0}-P_{0}\right) /\left(P_{0}\right) * 100
$$

$R=$ Accessibility index changes

$P_{0}=$ First year $P_{1+0}=$ Final year

\subsection{Accessibility changes based on population from 1996 to 2005}

Municipal regions can be divided into 2 groups based on index accessibility changes:

1- Regions with a positive accessibility coefficient which includes region 11 with a maximum $65 \%$ of changes, regions 9 and 10 with a $37 \%$ change and regions 8 , 3,2 and 1 with the least changes.

2- Regions with a negative accessibility coefficient which includes region 7 with the maximum negative change $(-29.7 \%)$. The situation of the other regions $(4,5$, 6 and 12) is shown in figure 3. The reduction of index accessibility changes in populated low income regions and its positive growth towards developed regions is increasing. It displays decentralization of the accessibility coefficient in the city region.

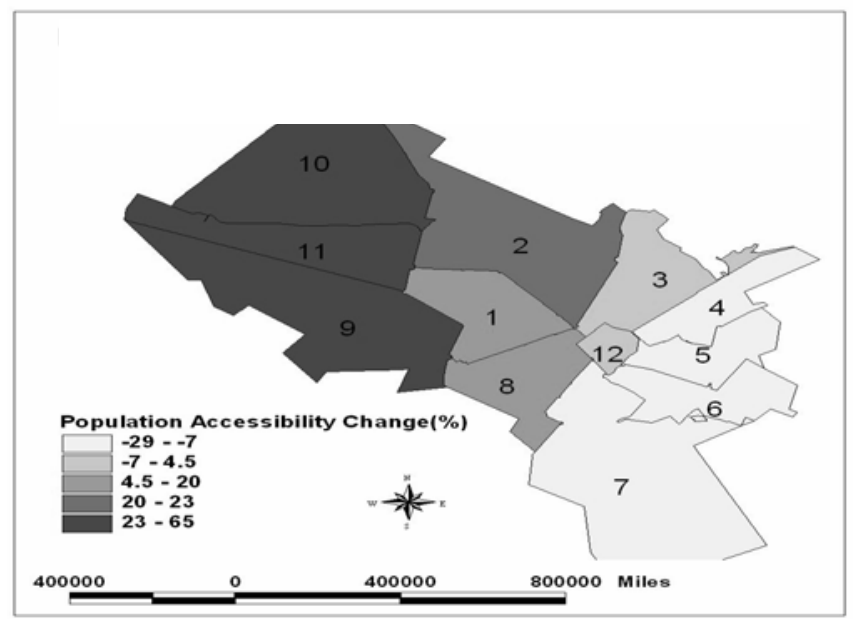

Figure 3: $\quad$ Mashhad population accessibility changes (1996-2005).

\subsection{Accessibility changes based on occupation from 1996 to 2005}

The number of employees of each region is one of the important factors which determines the attraction rate and shows the importance of the accessibility of that region. Accessibility changes based on occupation in the different regions of Mashhad are shown in figure 4 . The maximum accessibility changes in region 2 are $35 \%$ and the minimum in region 7 are $-19.6 \%$. Mashhad, with its index accessibility changes based on occupation is divided into 3 groups: 
1 - Regions with a positive and big index accessibility change, including regions $11,10,2,8,1$ and 9 in Mashhad, these regions are mainly in the west, north-west and south-east of Mashhad and one of the important features of thee regions is that they are developed and are populated high income regions.

2- Regions with a low accessibility coefficient change, these include regions 3, 4, 5 and 12, which shows the occupation decentralization in the central area of Mashhad and their growth towards developing regions of the city.

3- Regions with a negative accessibility coefficient change, these include regions 6 and 7 of Mashhad, and these regions have the lowest income and are situated in the city outskirts.

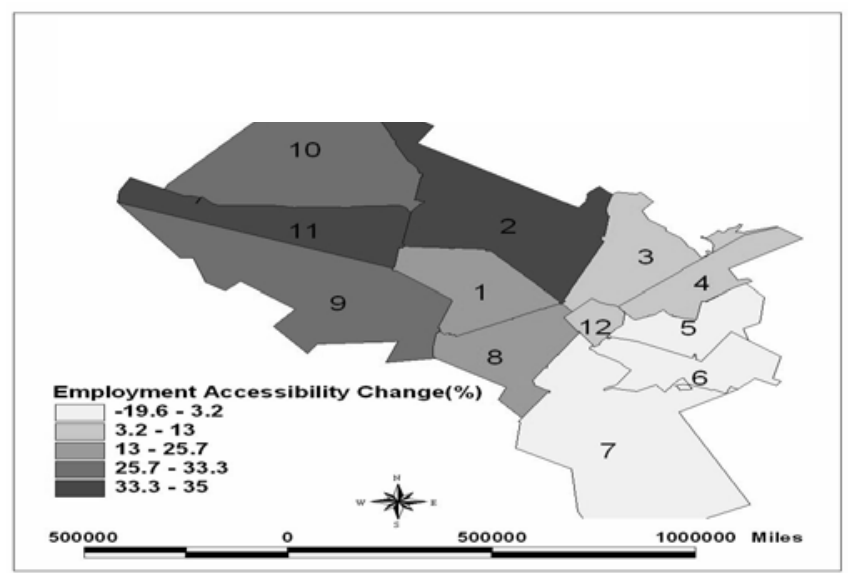

Figure 4: $\quad$ Mashhad Employment Accessibility Changes (1996-2005).

\section{Conclusions}

The results obtained from the accessibility evaluation based on population indexes, occupation, minimum distance and direct accessibility radius to the transportation system (buses) in the City of Mashhad indicate:

1- Approximately $12 \%$ of the city surface $(25,49$ square $\mathrm{km}$ ) and $14 \%$ of the population (342987 people) do not have direct accessibility to the bus system. Also the accessibility coefficient based on population and occupation shows great changes from 1996 to 2005 . There is an increase of the accessibility coefficient from the north-east and east towards the north-west and west, meaning from populated low income regions to developing regions with high incomes. The rate of the accessibility changes based on occupation is from highly populated regions and indicates the separation of the work place and residential areas. Meaning that decentralization in the spatial accessibility distribution, based on occupation, is more than the population of the city.

2- The challenges facing the creation of stable, complete accessibility plans with the Auto City model (Newman et al [15]). Including: the separation of land use 
applications; the ending of the governmental aid to municipalities from 1981 and their freedom to gain income; the scale of building density; changing the applications which are not according to city building laws; the illegal separation of residential parts (Kargar [16]); and the increase the per capita of cars for 1000 people from 54 to 80 from 1996 to 2005 in Mashhad, which has caused environmental and traffic problems.

Suggestion: By observing the increasing course of city bus transportation usage, using the Geographical Information System (GIS) to design new bus routes and changing the current routes, and applying new technology like buses with low floors for all social groups including the disabled and the security of bus stops, are factors which we should have in mind simultaneously.

\section{References}

[1] Salvo Giuseppe and Simona Sabitini, A GIS Approach to Evaluate Bus Stop Accessibility, Transport Department, Via Delle, Palermo, p. 265, 2006.

[2] A New South Wales Government Initiative, Action for Transport 2010, An Integrated Transport Plan for Sydney, pp.3 5, 2000

[3] Tehran Bus Organization, http://www.iran- daily.com/1383/2097 /html/panorama.htm\#10446

[4] Bus Stop Accessibility, http://www.dft.gov.uk/stellent/group/dftlocaltrasp/documents.

[5] Mashhad Bus Company, http://bus.mashhadnet.com/.

[6] Tavasoli, Mahmoud, Principals and City Designing Methods and Residential Spaces in Iran, vol.2, Accessibility Designing, Ministry of Housing and City Building, Tehran, 1992

[7] Ko-Wan Tsou, Yu-Ting Hung and Yao-Lin Chang, An Accessibilitybased integrated measures of relative spatial equity in urban public facilities, Cities, Vol.22, No.6, pp 424 435,2005.

[8] Levine Jonathan and Yaakov Garb, Congestion pricing conditional promise: promotion of accessibility or mobility, Transport Policy, 9,p.180, 2002.

[9] Lau Joseph C.Y and Catherine C.H Ciu, Accessibility of Low income workers in Hong Kong, Cities, Vol 20, No.3, pp.197 204, 2003.

[10] Bordde Makri Maria, Accessibility Indices. A tool for comprehensive land use planning, division of traffic planning, department of technology and society, Lund University, p.3, 1999. http://www.infra.kth.se/tla/tlenet/ meet5/papers/Makri.PDF

[11] Ber van Wee, Michel Hagtoort, Jan Anne Annema, Accessibility measures with competition, Journal of Transport Geography, vol.9, p. 200, 2001.

[12] Imam, Seyyed Kazem, Mashhad, Buzar Jumhuri Publications, Malek Publishing Company, Tehran, p.43, 1948.

[13] Transportation and Traffic Organization of the Mashhad Municipality Office, Second Transportation Survey of Mashhad, p. 4, 2005. 
378 Urban Transport XIII: Urban Transport and the Environment in the 21st Century

[14] Rahnamma, Mohammad Rahim, Anna Lyth, Measuring Accessibility Index in Metropolitan Sydney Area 1991-2001, Third Health Risk Conference, Waxes Institute, Bologna, Italy, p.345, 2004.

[15] Newman, Peter, et al, Sustainability and Cities; overcoming automobile dependences, Island Press, USA, p 63, 1999.

[16] Kargar Motlagh, Ahmad, Financial Resources of Municipalities, Challenges and Methods, First Seminar of Municipalities and City Finance, the Municipality Organization of the Country, Tehran, p.45, 2004. 